\title{
CORRECTION
}

\section{Correction to: Imaging spectrum of mesenteric masses}

\author{
Radwan Diab $^{1} \cdot$ Mayur Virarkar $^{1} \cdot$ Mohammed Saleh $^{1} \cdot$ Sherif Elsheif $^{1} \cdot$ Sanaz Javadi $^{1} \cdot$ Priya Bhosale $^{1} \cdot$ Silvana Faria $^{1}$
}

Published online: 18 July 2020

(c) Springer Science+Business Media, LLC, part of Springer Nature 2020

\section{Correction to: Abdominal Radiology}

https://doi.org/10.1007/s00261-020-02535-1

The original version of this article unfortunately contained a mistake. The author list was not correct in the original article. The missing co-author's name, Sherif Elsheif, has been added to show the correct and complete author list. All authors and the Editor-in-Chief agreed to the corrected author list. The original article has been corrected.

Publisher's Note Springer Nature remains neutral with regard to jurisdictional claims in published maps and institutional affiliations.

The original article can be found online at https://doi.org/10.1007/ s00261-020-02535-1.

Radwan Diab

RDiab@mdanderson.org

1 Department of Abdominal Imaging, The University of Texas MD Anderson Cancer Center, 1400 Pressler St., Houston, TX 77030, USA 